Egbert Brieskorn (Hrsg.)

Felix Hausdorff zum Gedächtnis

Band I 


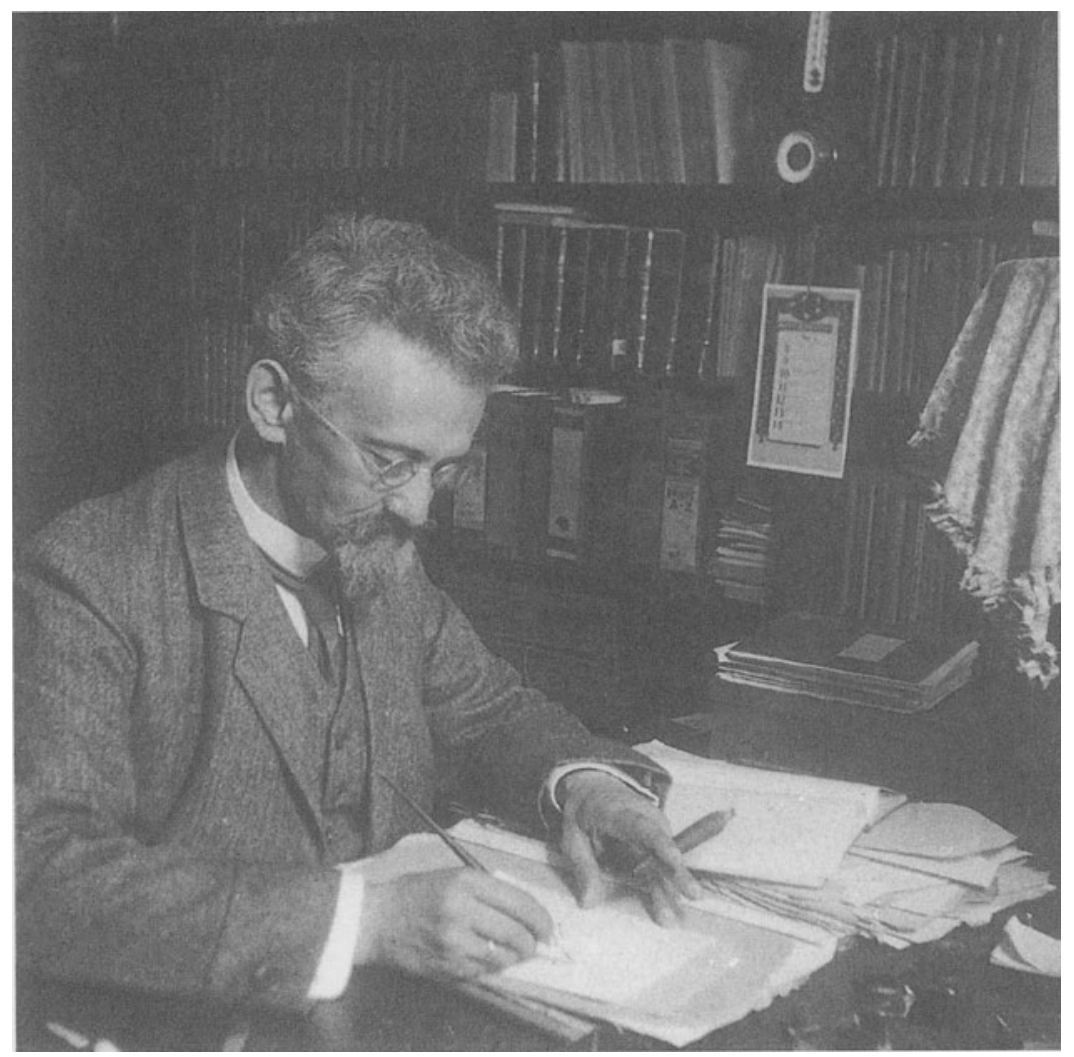

Felix Hausdorff im Arbeitszimmer seines Hauses in Bonn, Hindenburgstraße 61, im Juni 1924. 
Egbert Brieskorn (Hrsg.)

\title{
Felix Hausdorff zum Gedächtnis
}

\author{
Band I \\ Aspekte seines Werkes
}


Die Deutsche Bibliothek - CIP-Einheitsaufnahme

Felix Hausdorff zum Gedächtnis / Egbert Brieskorn (Hrsg.). -

Braunschweig; Wiesbaden: Vieweg.

NE: Brieskorn, Egbert [Hrsg.]

Bd. 1. Aspekte seines Werkes. - 1996

ISBN-13: 978-3-322-80277-4

e-ISBN-13: 978-3-322-80276-7

DOI: $10.1007 / 978-3-322-80276-7$

Bildnachweis: Seite II

Photograph: Ludwig Hogrefe

Das Original, ein Stereobildpaar, befindet sich im Nachlaß von Felix Hausdorff in der Handschriftenabteilung der Universitäts- und Landesbibliothek Bonn.

Alle Rechte vorbehalten

(c) Friedr. Vieweg \& Sohn Verlagsgesellschaft mbH, Braunschweig/Wiesbaden, 1996

Softcover reprint of the hardcover 1st edition 1996

Der Verlag Vieweg ist ein Unternehmen der Bertelsmann Fachinformation GmbH.

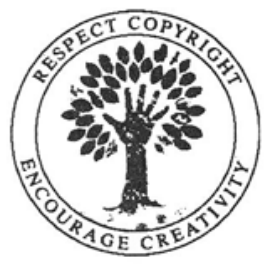

Das Werk einschließlich aller seiner Teile ist urheberrechtlich geschützt. Jede Verwertung außerhalb der engen Grenzen des Urheberrechtsgesetzes ist ohne Zustimmung des Verlags unzulässig und strafbar. Das gilt insbesondere für Vervielfältigungen, Übersetzungen, Mikroverfilmungen und die Einspeicherung und Verarbeitung in elektronischen Systemen. 


\section{Inhalt}

\section{Egbert Brieskorn}

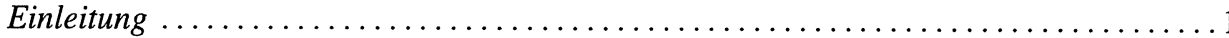

\section{Hans-Joachim Ilgauds}

Die frühen Leipziger Arbeiten Felix Hausdorfs . .

Hans-Joachim Girlich

Hausdorffs Beiträge zur Wahrscheinlichkeitstheorie

\section{Peter Koepke}

Metamathematische Aspekte der Hausdorfschen Mengenlehre

\section{Erhard Scholz}

Logische Ordnungen im Chaos: Hausdorfs frühe Beiträge zur Mengenlehre

\section{Peter Schreiber}

Felix Hausdorffs paradoxe Kugelzerlegung im Kontext der Entwicklung

von Mengenlehre, Maßtheorie und Grundlagen der Mathematik

\section{Christoph Bandt und Hermann Haase}

Die Wirkungen von Hausdorffs Arbeit über Dimension und äußeres Maß

\section{Klaus Steffen}

Hausdorff-Dimension, reguläre Mengen und total irreguläre Mengen

\section{Hans-Günther Bothe und Jörg Schmeling}

Die Hausdorff-Dimension in der Dynamik

\section{Erwin Neuenschwander}

Felix Hausdorffs letzte Lebensjahre nach Dokumenten

aus dem Bessel-Hagen-Nachlaß

\section{Günter Bergmann}

Die vom Lande NRW 1980 erworbenen Schriftstücke

aus dem Nachlaß Felix Hausdorfs.

Claus Hertling

Verzeichnis der mathematischen Schriften Felix Hausdorfs 